\title{
Empirical Analysis of the Influence of Dongguan's Modern Logistics Industry on Import and Export Trade
}

\author{
Luo Xiaoqin $^{1, *}, \mathrm{Xu}$ Weiyu ${ }^{1}$, and Shi Jiabiao ${ }^{1}$ \\ ${ }^{1}$ Quantitative Economics, International Economics and Trade, Lecturer title ,China
}

\begin{abstract}
In recent years, with the rapid economic development and the deepening of global economic integration, import and export trade has developed rapidly. With the development of international trade, international logistics has emerged. Modern logistics is a necessity for import and export trade, and the development of logistics has a direct influence on the development of import and export. In order to adapt to the rapid development of import and export trade, the modern logistics industry is developing in the direction of quality, diversity and efficiency. As the manufacturing capital, Dongguan has great potential for trade development. Relying on the superior geographical environment and the original industrial system, and further integrating resources on this basis, Dongguan vigorously develops its modern logistics industry and promotes a high degree of connection between international trade and characteristic industries, promoting the development of Dongguan's import and export trade. Taking Dongguan as the research object and combining the data of Dongguan's import and export trade and modern logistics industries, this paper established a quadratic curve fitting model to analyze the relationship between the total transportation volume and the total import and export volume, conducted elasticity and marginal analysis based on the empirical results, and put forward feasible suggestions for the development of Dongguan's logistics and import and export trade.
\end{abstract}

\section{Description of variables and data}

The level of foreign trade development of a region is generally measured by the total foreign trade volume of the region. In this paper, the total import and export trade of Dongguan is used as the dependent variable of the empirical analysis. Freight volume, port cargo throughput and container throughput are important indicators to measure the development level of the modern logistics industry which, in turn, is an important indicator of the development of foreign trade. Freight volume refers to the actual tonnage of goods transported by the transportation sector within a certain period of time, and can directly and objectively indicates the status of modern logistics. Port throughput, in tons, as another weight indicator, is not affected changes in other factors. In this paper, the model analysis takes the total import and export volume as the dependent variable and the total transportation volume (= freight volume + port throughput) as the independent variable. In Table $1, x$ is the total transportation volume and $\mathrm{y}$ is the total import and export volume.
Table1. Total transportation volume and total import and export volume from 2010 to 2019

\begin{tabular}{|c|c|c|c|c|}
\hline Year & $\begin{array}{c}\text { Port } \\
\text { throughput } \\
\text { (tons'100 } \\
\text { milion) }\end{array}$ & $\begin{array}{c}\text { Freight } \\
\text { volume } \\
\text { (tons'100 } \\
\text { million) }\end{array}$ & $\begin{array}{c}\text { Total } \\
\text { transportati } \\
\text { on volume } \\
\text { (tons' 100 } \\
\text { million) }\end{array}$ & $\begin{array}{c}\text { Total import } \\
\text { and export } \\
\text { volume } \\
\mathbf{( \$ ~ 1 0 0 ~} \\
\text { million) }\end{array}$ \\
\hline 2010 & 0.65657 & 0.9312 & 1.58777 & 1213.38 \\
\hline 2011 & 0.6848 & 1.0165 & 1.7013 & 1352.24 \\
\hline 2012 & 0.9228 & 1.1191 & 2.0419 & 1444.16 \\
\hline 2013 & 1.1187 & 1.2863 & 2.4050 & 1530.72 \\
\hline 2014 & 1.2900 & 1.5375 & 2.8275 & 1625.31 \\
\hline 2015 & 1.3149 & 1.5385 & 2.8534 & 1676.73 \\
\hline 2016 & 1.4584 & 1.5539 & 3.0123 & 1723.14 \\
\hline 2017 & 1.5714 & 1.6725 & 3.2439 & 1811.73 \\
\hline 2018 & 1.6417 & 1.7272 & 3.3689 & 2033.31 \\
\hline 2019 & 2.9808 & 1.7653 & 3.7461 & 2001.51 \\
\hline
\end{tabular}

Source: Dongguan Statistical Yearbook 2010-2019 


\section{Model building}

(I) Modeling and conception. The purpose of this paper is to study the influence of Dongguan's modern logistics industry on import and export trade to check whether the development of the modern logistics industry promotes import and export trade. In order to verify the correlation between the two, this paper made a scatter diagram using Dongguan's logistics and import and export data, conducted regression analysis and established a mathematical model. The theoretical equation is: $\mathrm{y}=\mathrm{ax} 2+\mathrm{bx}+\mathrm{c}$, where the dependent variable $\mathrm{y}$ represents total import and export volume of Dongguan in Table 1, the independent variable $\mathrm{x}$ represents total transportation volume of Dongguan in Table 1, and $\mathrm{c}$ is a constant. The quadratic curve fitting model in the SPSS software is used for data analysis because it can more intuitively show the degree of correlation between Dongguan's modern logistics industry and import and export trade.
(II) Parameter design and inspection. The quadratic curve fitting model was analyzed with the SPSS software and the regression results are shown in Tables 2, 3 and 4. It can be obtained from the results of analysis of variance in Table 3 that a is 29.293 , b is 204.832, and c is 868.471. It can be obtained from Table 2 that the determination coefficient R2 is 0.947 , and the adjusted determination coefficient is 0.931 . Since the determination coefficient $\mathrm{R} 2$ is close to 1 , it is concluded that there is a strong linear relationship between $\mathrm{x}$ and $\mathrm{y}$, that is, there is a high correlation between Dongguan's logistics industry and import and export trade. The research with this method has certain reference value. In regression analysis, the higher the goodness of fit, the greater the change of the dependent variable caused by the change of the independent variable, that is, the higher the former's degree of explanation of the latter. In Table 3, the significance of the variable is less than 0.05 , so the $T$ test can be passed. In addition, $\mathrm{F}$ is 62.004 , and $\mathrm{P}$ is 0.000 , less than 0.01 , so the $\mathrm{F}$ test can also be passed.

Table2. Model summary

\begin{tabular}{|c|c|c|c|}
\hline $\mathrm{R}$ & $\mathrm{R}^{2}$ & Adjusted $\mathrm{R}^{2}$ & Standard skewness error \\
\hline 0.973 & 0.947 & 0.931 & 69.809 \\
\hline
\end{tabular}

Table3. Analysis of variance

\begin{tabular}{|c|c|c|c|c|c|}
\hline & Tum of squares & df & Mean squared & F & Significance \\
\hline Regression & 604328.554 & 2 & 302164.277 & 62.004 & 0.000 \\
\hline Residual & 34112.932 & 7 & 4873.276 & & \\
\hline Total & 638441.486 & 9 & & & \\
\hline
\end{tabular}

Table4. Coefficients

\begin{tabular}{|c|c|c|c|c|c|}
\hline & \multicolumn{2}{|c|}{ Non-standardized coefficient } & $\begin{array}{c}\text { Standardized } \\
\text { coefficient }\end{array}$ & $\begin{array}{c}\text { T statistical } \\
\text { magnitude }\end{array}$ & Significance \\
\cline { 2 - 6 } & B & Standard error & Beta & 0.750 & 0.478 \\
\hline $\begin{array}{c}\text { Total transportation volume } \\
\text { (tons'100 million) }\end{array}$ & 204.832 & 273.144 & 0.557 & & 0.562 \\
\hline $\begin{array}{c}\text { Total transportation volume } \\
\text { (tons'100 million)**2 }\end{array}$ & 29.293 & 52.156 & 0.417 & 0.592 \\
\hline (constant) & 868.471 & 339.535 & & 2.558 & 0.038 \\
\hline
\end{tabular}

Table5. Elasticity values of Shenzhen's modern logistics-import and export trade

\begin{tabular}{|c|c|c|c|c|c|}
\hline Year & $\mathrm{t}$ & $\mathrm{dy} / \mathrm{dx}$ & $\mathrm{x} / \mathrm{y}$ & Eyx & \multirow{2}{*}{0.4812} \\
\hline 2010 & 1 & 297.38 & 0.00130 & 0.387 & 0.383 \\
\hline 2011 & 2 & 303.99 & 0.00126 & 0.457 \\
\hline 2012 & 3 & 323.85 & 0.00141 & 0.542 & \\
\hline 2013 & 4 & 345.01 & 0.00157 & 0.643 & \\
\hline 2014 & 5 & 369.64 & 0.00174 & 0.631 & \\
\hline 2015 & 6 & 371.15 & 0.00170 & 0.666 & \\
\hline 2016 & 7 & 380.41 & 0.00175 & 0.705 & \\
\hline 2017 & 8 & 393.91 & 0.00179 & 0.666 & \\
\hline 2018 & 9 & 401.19 & 0.00166 & 0.791 & \\
\hline
\end{tabular}


The correlation regression analysis above proves that the equation is significantly effective. The resulting regression equation is:

$$
y=29.293 x 2+204.832 x+868.471 z
$$

\section{Empirical analysis}

\section{(I) Elasticity analysis}

According to regression analysis, the development level of Dongguan's modern logistics industry has a high correlation with the development level of its foreign trade. According to the fitting regression model of the second part, elasticity analysis of the data is carried out here using the theory of economic elasticity in order to study the degree of response or sensitivity of changes in variables related to the dependent variable (total transportation volume) to changes in variables related to the independent variable (total import and export volume). The calculation formula is:

$$
\operatorname{Eyx}=(d y / y) /(d x / x)=(d y / d x) \times(x / y)
$$

Where, Eyx represents the elasticity of variable $y$ at point $\mathrm{x}$, that is, the percentage of $\mathrm{y}^{\prime}$ s change when $\mathrm{x}$ changes by $1 \%$; dy and $d x$ represent the amount of change of variables $\mathrm{y}$ and $\mathrm{x}$ respectively. Below, the elasticity of trade logistics is used to express the degree of response of logistics to changes in import and export trade.

From the regression equation, we can get:

$$
(\mathrm{dy} / \mathrm{dx})=58.286 \mathrm{x}+204.832
$$

Next, according to the calculation formula of elasticity theory, we can calculate the elasticity coefficient Eyx from 2010 to 2019 (Table 5).

It can be concluded from Table 5 that in the past ten years, the elasticity coefficient of Dongguan's foreign trade logistics has shown an overall upward trend, showing a positive correlation. At the same time, it can be concluded that the development of modern logistics industry has significant influence on import and export trade, and the influence is increasing every year. In 2020, Dongguan's total transportation volume of Dongguan increased by $1 \%$ and its total import and export volume increased by $0.387 \%$, while in 2019 , Dongguan's total transportation volume increased $1 \%$ and its total import and export volume increased by $0.791 \%$. According to calculations and statistics, the average elasticity coefficient from 2010 to 2019 is 0.5865 , which indicates that without considering other factors, for every $1 \%$ increase in the total transportation volume, Dongguan's total import and export trade volume increases by $0.5865 \%$. Therefore, the development of Dongguan's modern logistics industry can greatly promote the development of Dongguan's import and export trade.

(II) Marginal analysis

The changes of $\triangle X$ and $\triangle y$ were obtained through derivative operations on the quadratic curve fitting equation, and marginal analysis was carried out. The data from 2010 to 2019 was derived, and a judgment was made from the result data of marginal analysis on whether Dongguan's modern logistics industry plays a role in promoting its import and export trade. The derivative equation is $(\mathrm{dy} / \mathrm{dx})=58.286 \mathrm{x}+204.832$. Because $\mathrm{x}$ is greater than 0 , the result of the derivative operation will always be greater than 0 , indicating that there is a positive correlation between the development of Dongguan's modern logistics industry and Dongguan's import and export trade. Therefore, the development of Dongguan's modern logistics industry promotes the development of Dongguan's import and export trade.

Table6. Marginal analysis results

\begin{tabular}{|c|c|}
\hline Year & Marginal analysis \\
\hline 2010 & 297.38 \\
\hline 2011 & 303.99 \\
\hline 2012 & 323.85 \\
\hline 2013 & 345.01 \\
\hline 2014 & 369.64 \\
\hline 2015 & 371.15 \\
\hline 2016 & 380.41 \\
\hline 2017 & 393.91 \\
\hline 2018 & 401.19 \\
\hline 2019 & 423.18 \\
\hline Marginal analysis & 360.971 \\
\hline mean & \\
\hline
\end{tabular}

The results of marginal analysis in Table show that the marginal analysis mean is $\$ 36.0971$ billion, that is, for every increase of 100 million tons of Dongguan's total transportation volume, its import and export trade volume will increase by $\$ 36.0971$ billion. Therefore, the relevant departments of Dongguan should pay attention to the development of modern logistics industry, develop appropriate preferential policies and improve the technology and theory to promote the overall development of Dongguan's modern logistics industry.

\section{Conclusions and suggestions}

\section{(I) Conclusions}

The results of the empirical analysis show that the development of Dongguan's modern logistics industry can improve the level of its import and export trade to a certain extent. When its total transportation volume increases by $1 \%$, its import and export volume increases by $0.5865 \%$; when the total transportation volume increases by 100 million tons, the total import and export volume increases by $\$ 36.097,1$ billion. According to the data analysis above, there is an obvious positive correlation between Dongguan's modern logistics and import and export trade, that is to say, the development of 
modern logistics plays an obvious role in promoting import and export trade in Dongguan.

Table 5 indicates that the mean of trade logistics elasticity is 0.4812 from 2010 to 2014 and 0.6918 from 2015 to 2019, the former figure being smaller than the latter and the overall elasticity being increasing. It can be concluded from Table 6 that the influence of changes in total transportation volume on total import and export volume is also increasing. The elasticity and marginal analysis of Table 5 and Table 6 show that the development of modern logistics industry has an increasing degree of influence on import and export trade.

(II) Suggestions

Whether in economically prosperous areas or relatively backward areas, the development of modern logistics industry plays a vital role in the development of import and export trade, and they always have positive correlation. Therefore, if we want to increase our efforts to develop foreign trade, we should start from modern logistics technology. The modern logistics industry refers to the entire process of the effective flow of raw materials and finished products from the starting point to the end point. The process is an organic combination of transportation, warehousing, loading and unloading, processing, packaging, sorting, distribution, information and other aspects, forming a complete supply chain. These steps are interlocking and indispensable. How to complete these processes accurately and efficiently? This requires the support of computer technology and the reform and innovation of logistics technology and equipment to improve logistics efficiency and logistics environment. Strong support from relevant national policies is also needed. According to the analysis of the promotion effect of the development of Dongguan's modern logistics industry on its import and export trade, combined with the relevant research results of other scholars, this paper puts forward some opinions on the development of Dongguan's logistics industry.

1. Reduce transportation costs

The proportion of Dongguan's annual investment in the development of modern logistics industry has shown an overall upward trend. However, as far as the current situation is concerned, there is still a lot of room for growth in the development of Dongguan's modern logistics industry. At present, the operation technology of modern logistics is cumbersome and mechanized and fully automated logistics technology has not yet reached the standard, which has increased the time and labor cost of the entire logistics process. Therefore, the high logistics cost has become an important factor hindering the development of modern logistics industry. It is advised to appropriately reduce logistics and transportation costs and unnecessary fees, such as tolls, customs clearance fees, etc. In addition, government preferential policies and financial subsidies can be used to reduce the burden on logistics enterprises.

2. Establish a special logistics supervision department

In recent years, the modern transportation industry has developed rapidly. It has comprehensively covered all kinds of transportation routes, including air transportation, land transportation (road and railway), water transportation and pipeline transportation. Multiple modes of transportation go hand in hand and involve transportation, industry and commerce, customs and many other government departments. Due to the different operation methods and management standards of various departments, the management of multiple departments has restricted the effective integration of resources of logistics enterprises and reduces the efficiency of logistics and transportation to a certain extent. To solve this shortcoming, the government must establish a centralized logistics management department to specifically deal with matters related to the transportation of import and export goods and conduct standardized and unified management of existing logistics enterprises. 3. Improve the informatization, automation and intelligence of the logistics industry

Currently, the tracking and monitoring of the logistics information of import and export goods in Dongguan is not accurate and comprehensive, and the detailed status of goods cannot be accurately obtained. The lack of an intelligent and accurate logistics information tracking system makes it impossible for enterprise users to obtain detailed information of goods other than the transportation status in real time. Therefore, the top priority is to accelerate the integration of science and technology and Internet technology with modern logistics to promote the modernization of the logistics and transportation industry. At the same time, it is necessary to avoid resource waste caused by resource overlap; it is advised to rationally use resources, strengthen cooperation with domestic Internet enterprises such as Alibaba with its cloud platform and databases and Huawei's 5G and software technology, build a modern international logistics and transportation platform, track and monitor import and export goods transportation, query logistics information in real time, and improve the transparency of logistics transportation. In addition, it is advised to speed up the construction of smart warehouses to realize automatic sorting and smart identification so that automated and smart logistics can fully cover the entire process of modern logistics, thereby reducing the operation time of each link of logistics to improve the efficiency of logistics and transportation and save labor cost.

\section{Project Name}

General Project of Guangdong University of Science and Technology, Research on the Industrial Transformation and Upgrade Path of Dongguan under the Location Advantage

Project number: GKY-2017KYYB-14

\section{References:}

1. Pan Xuhong, An Exploration of the Impact of the Logistics Industry on the Development of International Trade and the Countermeasures [J], Shangqing, 2020, 39:153-154.

2. Shan Qining, Analysis of the Development Status of Contemporary International Trade and Logistics Industry [J], China Market, 2020, 19:172. 
3. Liao Changzuo, The Impact of the Development of the Logistics Industry on International Trade [J], Fortune Today, 2018, 21:008.

4. Zhu Shiyan, Liu Chongxian, Empirical Research on the Impact of "Belt and Road" International Logistics Performance on China's Export Trade [J], 2021, 44(01):025. 